\title{
Regulation and function of AMPK in physiology and diseases
}

\author{
Sang-Min Jeon \\ 5'-adenosine monophosphate (AMP)-activated protein kinase (AMPK) is an evolutionarily conserved serine/threonine kinase that \\ was originally identified as the key player in maintaining cellular energy homeostasis. Intensive research over the last decade has \\ identified diverse molecular mechanisms and physiological conditions that regulate the AMPK activity. AMPK regulates diverse \\ metabolic and physiological processes and is dysregulated in major chronic diseases, such as obesity, inflammation, diabetes \\ and cancer. On the basis of its critical roles in physiology and pathology, AMPK is emerging as one of the most promising \\ targets for both the prevention and treatment of these diseases. In this review, we discuss the current understanding of the \\ molecular and physiological regulation of AMPK and its metabolic and physiological functions. In addition, we discuss the \\ mechanisms underlying the versatile roles of AMPK in diabetes and cancer.
}

Experimental \& Molecular Medicine (2016) 48, e245; doi:10.1038/emm.2016.81; published online 15 July 2016

\section{MOLECULAR REGULATION OF 5'-ADENOSINE MONOPHOSPHATE (AMP)-ACTIVATED PROTEIN KINASE (AMPK)}

The basic and emerging molecular mechanisms of AMPK regulation are discussed below and summarized in Figure 1.

Basic mechanisms: adenylate charge, calcium and T172 phosphorylation

AMPK is a heterotrimeric complex containing one catalytic $\alpha$-subunit and two regulatory $\beta$ - and $\gamma$-subunits. ${ }^{1}$ In mammals, AMPK $\alpha$ - and $\beta$-subunits have two isoforms each, and AMPK $\gamma$-subunit has three isoforms. This suggests the presence of 12 potential combinations of AMPK, each with different functions under different physiological conditions. ${ }^{2}$ Several studies have suggested that these isoforms of AMPK subunits behave and are regulated differently under different physiological conditions. $^{2,3}$ AMPK is regulated both allosterically and by post-translational modifications. The most well-defined mechanisms of AMPK activation are phosphorylation at T172 of the $\alpha$-subunit and by AMP and/or adenosine diphosphate (ADP) binding to $\gamma$-subunit. ${ }^{4}$ Adenosine triphosphate (ATP) competitively inhibits the binding of both AMP and ADP to the $\gamma$-subunit, which suggests that AMPK is a sensor of AMP/ATP or ADP/ATP ratios.

Phosphorylation at T172 of the AMPK $\alpha$-subunit is regulated by at least three kinases and three phosphatases: namely, liver kinase B1 (LKB1), which exists in a heterotrimeric complex with STRAD and MO25; calcium-/calmodulin-dependent kinase kinase 2 (CaMKK2); TGF $\beta$-activated kinase 1 (TAK1); protein phosphatase 2A (PP2A); protein phosphatase 2C (PP2C) and $\mathrm{Mg}^{2+}-/ \mathrm{Mn}^{2+}$-dependent protein phosphatase $1 \mathrm{E}$ (PPM1E). ${ }^{5-12}$ In energy-replete conditions, that is, in the presence of low AMP/ATP and ADP/ATP ratios, phosphatases can easily access T172 of the AMPK $\alpha$-subunit to keep it in the unphosphorylated state. However, when energy is depleted, high levels of AMP and ADP bind to CBS3 of the AMPK $\gamma$-subunit, which prevents the phosphatases from accessing T172 of the AMPK $\alpha$-subunit, thus increasing its phosphorylation. In addition, binding of AMP and (to a lesser extent) ADP to CBS3 stimulates LKB1-mediated phosphorylation, which requires myristoylation of the AMPK $\beta$-subunit. ${ }^{13}$ Finally, the binding of AMP, but not of ADP, to CBS1 increases intrinsic AMPK activity by inducing its allosteric activation. In addition to the binding of adenylates, the binding of glycogen, especially glycogen with high branch points, to the $\beta$-subunit inhibits AMPK; however, the physiological significance of this is unclear. ${ }^{14}$ Intracellular calcium activates AMPK through CaMKK2-mediated phosphorylation. TAK1, a MAPKKK family member (MAP3K7), also phosphorylates and activates AMPK; however, the physiological conditions under which the TAK1-AMPK pathway operates remain to be elucidated. ${ }^{15,16}$

College of Pharmacy and Institute of Pharmaceutical Science and Technology, Ajou University, Gyeonggi-do, Republic of Korea

Correspondence: Professor S-M Jeon College of Pharmacy and Institute of Pharmaceutical Science and Technology, Ajou University, 206, World cup-ro, Yeongtong-gu, Suwon, Gyeonggi-do 16499, Republic of Korea.

E-mail: smjeon@ajou.ac.kr

Received 13 April 2016; revised 23 April 2016; accepted 26 April 2016 

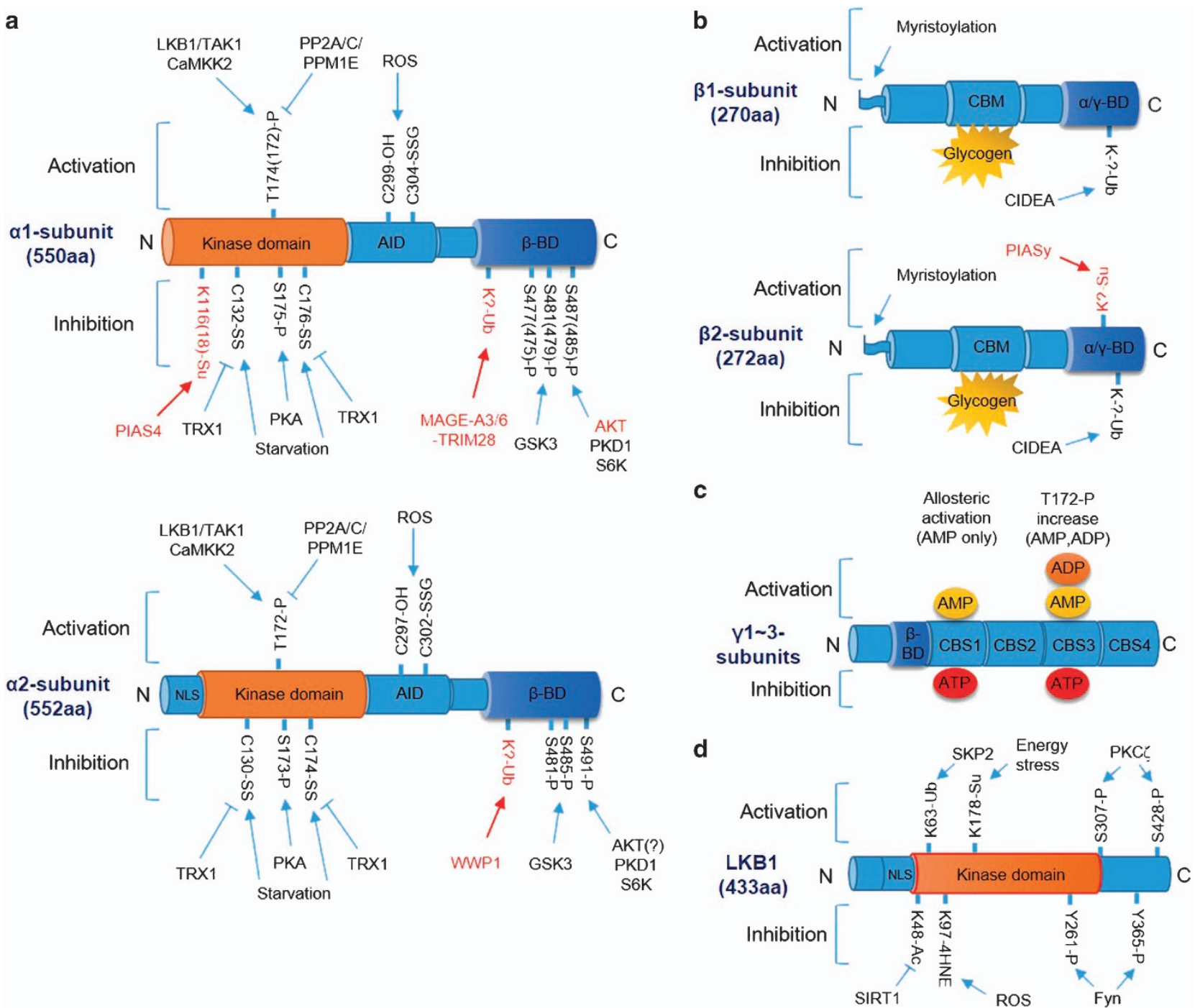

Figure 1 Molecular regulation of AMPK and LKB1. (a) Modification of the AMPK $\alpha 1$ (top) and $\alpha 2$ (bottom) subunits by phosphorylation/ dephosphorylation, ubiquitination, sumoylation and oxidation/reduction. Pathways marked in red indicate $\alpha 1$ - or $\alpha 2$-subunit-specific modifications. Numbers of modified amino acids are based on human proteins, and numbers in parenthesis are those reported in the original research (see text for details). (b) Modification of the AMPK $\beta 1$ (top) and $\beta 2$ (bottom) subunits by myristoylation, ubiquitination, sumoylation and glycogen binding. Pathways marked in red indicate $\beta 1$ - or $\beta 2$-subunit-specific modifications (see text for details). (c) Modification of the AMPK $\gamma$-subunit by AMP, ADP or ATP binding. Binding of AMP to CBS1 induces allosteric activation, and binding of AMP or ADP to CBS3 induces T172 phosphorylation (see text for details). (d) Modification and regulation of LKB1 by phosphorylation, acetylation, ubiquitination, sumoylation and 4HNE adduction (see text for details). Arrow indicates activation, and bar-headed line indicates inhibition. $\alpha / \gamma$-BD, $\alpha / \gamma$-subunit-binding domain; AID, autoinhibitory domain; $\beta$-BD, $\beta$-subunit-binding domain; CBM, carbohydratebinding module; CBS, cystathionine beta-synthase domain; NLS, nuclear localization signal.

\section{Emerging mechanisms}

Phosphorylation. Insulin inhibits AMPK by inducing its direct phosphorylation by AKT. AKT phosphorylates S485 of the AMPK $\alpha 1$-subunit (S487 in humans) but does not phosphorylate an equivalent site in the AMPK $\alpha 2$-subunit (S491), thus blocking upstream kinases from phosphorylating T172. ${ }^{17}$ Interestingly, a recent study showed that GSK3-induced phosphorylation at T479 of the AMPK $\alpha 1$-subunit is required for the AKT-mediated inhibition of AMPK and vice versa, suggesting that an association between AKT and GSK3 is required for insulin-induced inhibition of AMPK. ${ }^{18}$ The satiety hormone leptin also inhibits AMPK by inducing p70S6K-dependent phosphorylation at S491 of the $\alpha 2$-subunit. ${ }^{19}$ Furthermore, diacylglycerol (DAG), whose levels increase during hyperglycemia and hyperlipidemia, inhibits AMPK by inducing its direct phosphorylation by protein kinase $\mathrm{C}$ (PKC). A recent study showed that specifically PKD1 (PKC $\mu$ ), one of the PKC isoforms, phosphorylates S491 of the AMPK $\alpha 2$ subunit. ${ }^{20}$ Finally, protein kinase A (PKA) also inhibits AMPK by phosphorylating S173 of the $\alpha 1$-subunit, which blocks upstream kinases, such as LKB1 and CaMKK2, from phosphorylating T172. ${ }^{21}$

Ubiquitination/sumoylation. Ubiquitination inhibits AMPK by inducing its degradation. CIDEA, a cell death-inducing 
DNA fragmentation factor 45-like effector (CIDE) family protein, interacts with and ubiquitinates the AMPK $\beta$-subunit in brown adipose tissue. ${ }^{22}$ However, the exact mechanisms underlying this are unclear. In addition, both the testisrestricted melanoma antigen MAGE-A3/6 and TRIM28 ubiquitin ligase complex ubiquitinate the AMPK $\alpha 1$-subunit and are overexpressed in cancer cells, thus inducing its cancerspecific degradation. ${ }^{23} \mathrm{WW}$ domain-containing E3 ubiquitin protein ligase 1 also mediates the degradation of the AMPK $\alpha 2$-subunit through ubiquitination in the presence of high glucose levels. ${ }^{24}$ A recent study showed that SUMO E3 ligase PIAS4 catalyzes the sumoylation and inhibition of the AMPK $\alpha 1$-subunit, which elicits specific activation of the mechanistic target of rapamycin complex 1 (mTORC1). ${ }^{25}$ However, sumoylation by PIASy, which specifically targets the AMPK $\beta 2$-subunit, also activates AMPK and antagonizes its CIDEAinduced ubiquitination at the C-terminal of the $\beta 2$-subunit. ${ }^{26}$

Oxidation. A growing body of evidence suggests that the reactive oxygen species (ROS) regulate AMPK activity, although the mechanism is controversial. ${ }^{27,28}$ Interestingly, recent studies showed that oxidative stress and energy stress differentially regulate AMPK activity through direct oxidation at cysteine residues in AMPK. In HEK293 cells, hydrogen peroxide activates AMPK through oxidation and S-glutathionylation at C299/C304 of its $\alpha$-subunit. ${ }^{29}$ However, the oxidation at C130/C174 of the AMPK $\alpha$-subunit induced by $\mathrm{H}_{2} \mathrm{O}_{2}$ produced by glucose deprivation inhibits AMPK by promoting its aggregation and disrupting its interaction with upstream kinases. ${ }^{30}$ The opposing effects of AMPK oxidation by different sources of ROS seem to be dependent on the abundance of nutrients and the antioxidant capacity of cells because energy stress-induced oxidation and inhibition of AMPK was reversed by the expression of antioxidant enzyme thioredoxin-1 (TRX1). ${ }^{30}$

Protein-protein interactions/subcellular localization. AMPK activity can also be regulated by protein-protein interactions and its subcellular distribution. Although the mechanism is poorly understood, folliculin (FLCN), a tumor suppressor associated with Birt-Hogg-Dube syndrome, and its binding partners folliculin interacting protein-1 (FNIP-1) and -2 (FNIP-2) have been shown to interact with and inhibit AMPK. ${ }^{31,32}$ Interestingly, FLCN deficiency promotes metabolic transformation by activating the AMPK-peroxisome proliferator-activated receptor gamma coactivator $1 \alpha(\mathrm{PGCl} 1 \alpha)$-hypoxia inducible factor $1 \alpha$ axis. ${ }^{33}$ The sestrin family of proteins interacts with AMPK and leads to the activation of the AMPK-TSC2 signaling axis to inhibit mTORC1. ${ }^{34}$ In addition, upon AMP-dependent conformational change of AMPK, the scaffold protein axin promotes LKB1-AMPK complex formation, which enables efficient phosphorylation and activation of AMPK by LKB1 during energy stress. ${ }^{35}$

$N$-myristoylated AMPK $\beta$-subunit serves as a scaffolding protein that recruits the AMPK $\alpha$ - and $\gamma$-subunits to intracellular membranes, including the mitochondrial membranes, in response to energy stress. ${ }^{36}$ The nuclear localization signal (NLS) present in the $\alpha 2$-subunit, but not in the $\alpha 1$-subunit, is critical for the nucleocytoplasmic translocation of AMPK, suggesting that $\alpha 1$-subunit-containing AMPK mainly phosphorylates cytosolic substrates that regulate acute effects and that $\alpha 2$-subunit-containing AMPK mainly phosphorylates transcriptional machinery that regulates gene expression for long-term effects. ${ }^{37}$ In neurons, the AMPK $\gamma 1$-subunit preferentially localizes to the nucleus compared to other AMPK $\gamma$-subunits; however, the mechanisms underlying this translocation have not been explored to date. ${ }^{38}$

LKB1 modification. The classic view suggests that LKB1 is constitutively active. However, accumulating data suggest that LKB1 activity is regulated by various physiological stimuli that induce post-translational modifications as summarized in Figure 1d. Because LKB1 contains an NLS domain but not a nuclear export domain, it is generally localized to the nucleus. LKB1 activation occurs after it complexes with MO25 and STRAD $\alpha$, which induces its nuclear export and phosphorylation of its downstream targets, including AMPK, in the cytosol. LKB1 modifications that regulate its nucleocytoplasmic translocation for AMPK activation have been reported. PKCל phosphorylates S307/S428 (S399 for short form) of LKB1 and exports it to the cytosol, which is essential for AMPK activation. ${ }^{39-42}$ However, Fyn, a Src family non-receptor tyrosine kinase, phosphorylates Y261/Y365 of LKB1 to inhibit cytoplasmic translocation and AMPK activation. ${ }^{43}$ Importantly, SIRT1, a class III NAD-dependent histone deacetylase, deacetylates K48 of LKB1 to induce its cytoplasmic localization and AMPK activation. ${ }^{44} \mathrm{~A}$ recent study showed that metabolic stress triggers sumoylation at K178 of LKB1, which is essential for binding and phosphorylating AMPK ${ }^{45}$ Skp2-dependent ubiquitination at K63 of LKB1 activates LKB1 by maintaining the integrity of the LKB1-STRAD-MO25 complex and subsequently activates AMPK. ${ }^{46}$ Interestingly, adduct formation between K97 of LKB1 and 4HNE, a lipid peroxidation marker, during oxidative stress inhibits LKB1, and in turn, AMPK. ${ }^{47,48}$

\section{METABOLIC FUNCTIONS OF AMPK}

The key metabolic functions of AMPK are discussed below and summarized in Figure 2.

\section{Lipid metabolism}

The first known function of AMPK is the regulation of lipid metabolism. AMPK inhibits de novo synthesis of fatty acids (FAs), cholesterol and triglycerides (TGs), and activates FA uptake and $\beta$-oxidation (FAO). AMPK inhibits FA synthesis (FAS) by inducing the inhibitory phosphorylation of two targets: (1) acetyl-coA carboxylase 1 (ACC1), which catalyzes the rate-limiting step in FA synthesis by converting acetyl-coA to malonyl-coA, and (2) sterol regulatory element-binding protein 1c (SREBP1c), a transcription factor that promotes the expression of multiple lipogenic enzymes, including ACC1 and FA synthase. ${ }^{49,50}$ Excessive accumulation of FAs in cells are stored as TGs. The first committed step in TG synthesis is 


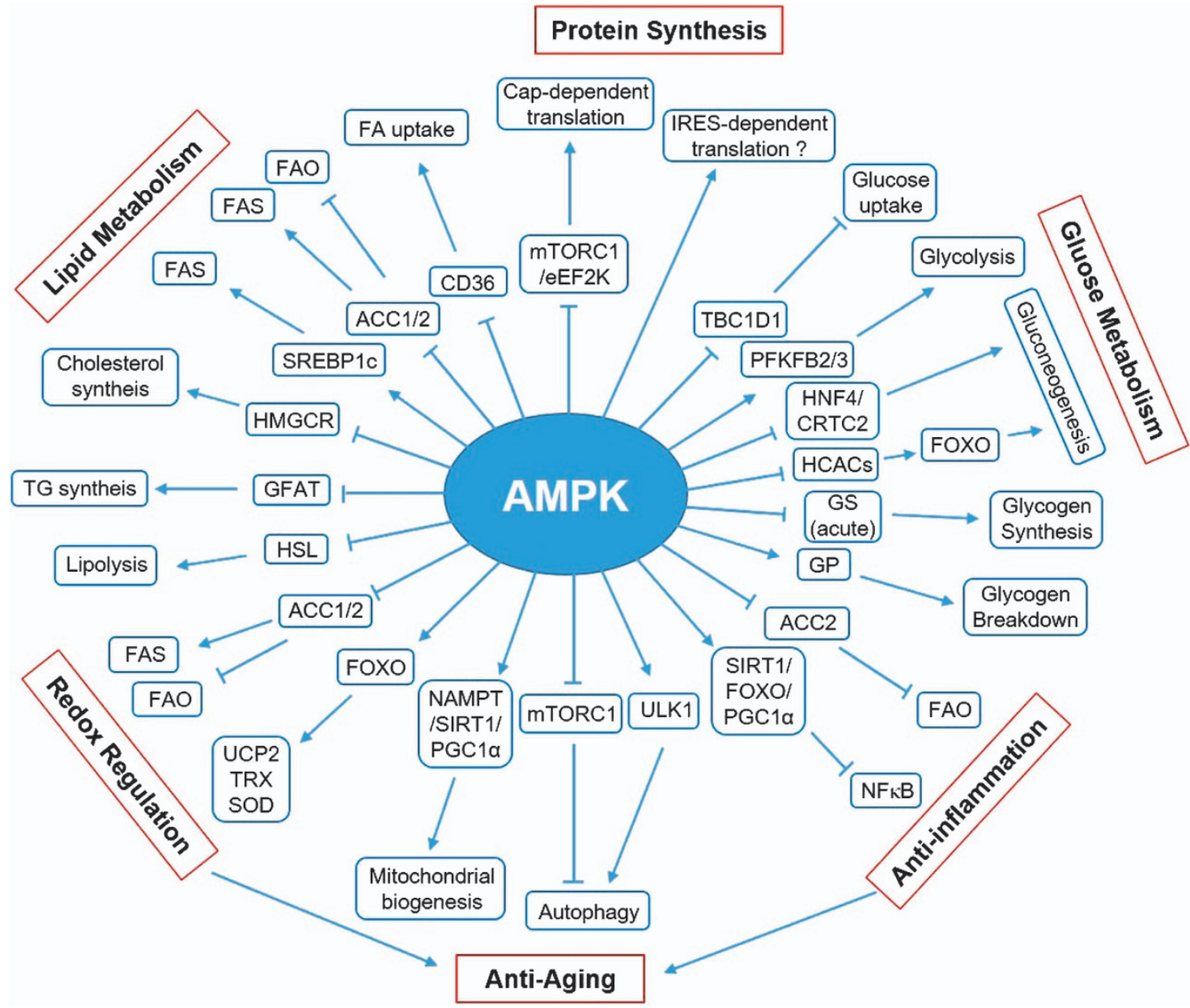

Figure 2 Metabolic functions of AMPK. A schematic summarizing the mechanisms underlying AMPK-induced regulation of diverse metabolic pathways. Arrow indicates activation, and bar-headed line indicates inhibition (see text for details).

catalyzed by glycerol-3-phosphate acyltransferase, which is inhibited by AMPK; however, it is unclear whether AMPK inhibits this step through direct phosphorylation or indirect regulation. ${ }^{51}$ AMPK also inhibits cholesterol synthesis by inducing the inhibitory phosphorylation of the rate-limiting enzyme HMG-CoA reductase. ${ }^{52}$

In addition to the inhibition of lipid anabolism, AMPK activates lipid catabolism. AMPK increases FA uptake by controlling the translocation of FA transporter CD36 to the plasma membrane; however, the mechanism underlying this is unclear. ${ }^{53}$ Once inside cells, FAs are transported into the mitochondria for $\beta$-oxidation by carnitine palmitoyltransferase-1 (CPT-1). AMPK increases CPT-1 activity and activates FAO by inducing the inhibitory phosphorylation of ACC2, which is localized to the outer membrane of the mitochondria near CPT-1 where it inhibits production of malonyl-CoA, a potent allosteric inhibitor of CPT- $1 .{ }^{50}$ However, AMPK inhibits lipolysis by inducing the inhibitory phosphorylation of hormone-sensitive lipase in the adipose tissue. ${ }^{54}$ These data suggest that the central role of AMPK in lipid metabolism involves controlling the concentration of circulating free FAs (FFAs) by activating FAO, and by inhibiting lipolysis and lipogenesis..$^{55}$

\section{Glucose metabolism}

In skeletal muscles, AMPK stimulates glucose uptake by translocating GLUT4-containing intracellular vesicles across the plasma membrane. Fusion of these vesicles with the plasma membrane requires Rab family $G$ proteins in their active GTP-bound state. AMPK phosphorylates and inhibits the Rab-GTPase-activating protein TBC1D1, which increases the activity of Rab family G proteins and induces fusion of GLUT4 vesicles with the plasma membrane. ${ }^{56}$ Interestingly, a recent study showed that AMPK also increases glucose uptake in HEK293 cells by blocking endocytosis and by promoting GLUT1 expression. ${ }^{57}$ AMPK-induced GLUT1 regulation is mediated by the phosphorylation and degradation of TRXinteracting protein, which induces GLUT1 internalization. AMPK also increases the mRNA expression of the genes encoding GLUT4 and hexokinase 2 to facilitate glucose uptake. ${ }^{58,59}$

After glucose is transported into the cells, it is phosphorylated by hexokinases to generate glucose-6-phosphate. Glucose6-phosphate is then consumed in several metabolic pathways including glycolysis, glycogen synthesis and pentose phosphate pathway. Among these pathways, glycolysis and glycogen synthesis are regulated by AMPK. Studies of cardiomyocytes, 
macrophages/monocytes and tumor cells indicate that AMPK stimulates glycolysis by phosphorylating and activating 6-phosphofructo-2-kinase/fructose-2,6-bisphosphatase 2/3, which produces fructose-2,6-bisphosphate, an allosteric activator of glycolytic enzyme phosphofructokinase- $1{ }^{60,61}$ AMPK inhibits glycogen synthesis through inhibitory phosphorylation of glycogen synthase (GS). However, chronic activation of AMPK can indirectly increase glycogen synthesis by increasing glucose uptake and glucose-6-phosphate production. This induces allosteric activation of GS that can overcome inhibitory phosphorylation by AMPK. ${ }^{62}$ Furthermore, AMPK also activates glycogen breakdown by phosphorylating and activating glycogen phosphorylase (GP).

Hepatic gluconeogenesis is important for maintaining blood glucose levels. AMPK inhibits gluconeogenesis by inhibiting several transcription factors, such as hepatocyte nuclear factor 4 (HNF4) and CREB regulated transcription coactivator 2 (CRTC2), that promote the expression of gluconeogenic enzymes, including phosphoenolpyruvate carboxykinase and glucose-6-phosphatase. ${ }^{63,64}$ In addition, AMPK can also inhibit gluconeogenesis by phosphorylating and inducing the nuclear exclusion of class IIa histone deacetylases, which normally deacetylate and activate transcription factor FOXO in the nucleus, which results in the expression of gluconeogenic enzymes during fasting. ${ }^{65}$

\section{Protein synthesis}

Protein synthesis is a high energy process that is inhibited during energy stress to conserve cellular ATP. AMPK inhibits cap-dependent translation during both initiation and elongation steps by indirectly inhibiting mTORC1 through the phosphorylation of TSC2 and raptor. Inhibition of mTORC1 activates 4EBP1 and inhibits p70S6K, thus inhibiting the initiation of cap-dependent translation and ribosomal proteins, respectively. AMPK also downregulates ribosomal RNA synthesis by inducing the inhibitory phosphorylation of transcription initiation factor 1A. ${ }^{66}$ Furthermore, AMPK directly inhibits translational elongation by phosphorylating and activating eEF2K, which phosphorylates and inhibits eEF2. ${ }^{67}$ However, expression of genes important for cell survival is also required during energy stress. ${ }^{68}$ Interestingly, AMPK can perform these functions by switching translation from cap-dependent to capindependent mechanisms. A recent study suggested that AMPK stimulates cap-independent and IRES-dependent translation of Hif- $1 \alpha$ during energy stress to induce the expression of genes critical for cell survival. ${ }^{69}$

\section{Autophagy and mitochondrial biogenesis}

Autophagy is a lysosome-dependent self-digestive process that maintains cellular integrity during nutrient deficiency. Recent studies have shown that AMPK activates autophagy by directly and indirectly activating ULK1, a mammalian homolog of ATG1. ${ }^{70,71}$ First, AMPK directly phosphorylates and activates ULK1 to induce autophagy. Second, AMPK indirectly activates ULK1 by inhibiting mTORC1, which phosphorylates and inhibits ULK1 to disrupt the ULK1-AMPK interaction. This coordinated regulation of ULK1 and mTORC1 eliminates damaged mitochondria and maintains mitochondrial integrity during nutrient starvation. ${ }^{70,71}$ In addition, the findings that FOXO upregulates expression of several autophagy inducers, such as Bnip3, LC3 and ATG12, and that AMPK phosphorylates and activates FOXO suggest that AMPK regulates autophagy by activating FOXO. Maintenance of mitochondrial integrity requires elimination of damaged mitochondria through autophagy and the production of fresh mitochondria through biogenesis. Moreover, autophagic degradation can contribute to energy generation by providing substrates for mitochondrial metabolism. Therefore, mitochondrial biogenesis is a crucial process for energy production and cellular response during nutrient deficiency. Pharmacological and genetic evidence indicates that AMPK regulates mitochondrial biogenesis by regulating $\mathrm{PGCl} \alpha$, a cofactor that promotes the transcription of nuclear-encoded mitochondrial genes. ${ }^{72-74}$ At least four mechanisms have been proposed to be involved in AMPK-induced PGC1 $\alpha$ activation: namely, direct phosphorylation of PGC1 $\alpha ;{ }^{75}$ activation of SIRT1-mediated deacetylation of PGCl $\alpha$ through an increase in $\mathrm{NAD}^{+} / \mathrm{NADH}$ ratio; AMPKdependent increase in nicotinamide phosphoribosyltransferase (NAMPT) expression ${ }^{76}$ or $\mathrm{FAO}^{77}$ and $\mathrm{p} 38$ MAPK-dependent increase in PGC1 $\alpha$ expression. ${ }^{78}$ SIRT1 activates AMPK by deacetylating LKB1 ${ }^{44}$ which suggests the presence of a positive feedback loop between AMPK and SIRT1.

\section{Redox regulation}

Because metabolism is interconnected with redox regulation, AMPK has a crucial role in regulating antioxidant defense during oxidative stress. AMPK upregulates several antioxidant genes, such as those encoding superoxide dismutase and uncoupling protein 2 , which reduce superoxide levels and thioredoxin (TRX), a disulfide reductase by phosphorylating and activating FOXO. ${ }^{79,80}$ Recent studies have suggested that NRF2, another transcription factor that is a master regulator of antioxidant response, is a potential target of AMPK to induce antioxidant defense. ${ }^{81,82}$ However, the mechanisms underlying this have yet to be elucidated. Furthermore, AMPK maintains NADPH levels by regulating FA metabolism through the phosphorylation and inhibition of ACC1/2 during metabolic stress. ${ }^{83} \mathrm{FA}$ synthesis is a major $\mathrm{NADPH}$-consuming process. In contrast, FAO produces NADPH by increasing TCA cycle metabolites malate and isocitrate, which are catabolized by the NADPH-producing enzymes malic enzyme 1 (ME1) and isocitrate dehydrogenase 1 (IDH1), respectively. Inhibition of FAS and activation of FAO by the AMPK-ACC1/2 axis detoxifies ROS by maintaining NADPH and GSH levels. These data suggest that AMPK regulates antioxidant defense through both short- and long-term effects.

\section{PHYSIOLOGICAL REGULATION OF AMPK}

The physiological contexts that regulate AMPK activity and their physiological consequences are discussed below and summarized in Figure 3. 


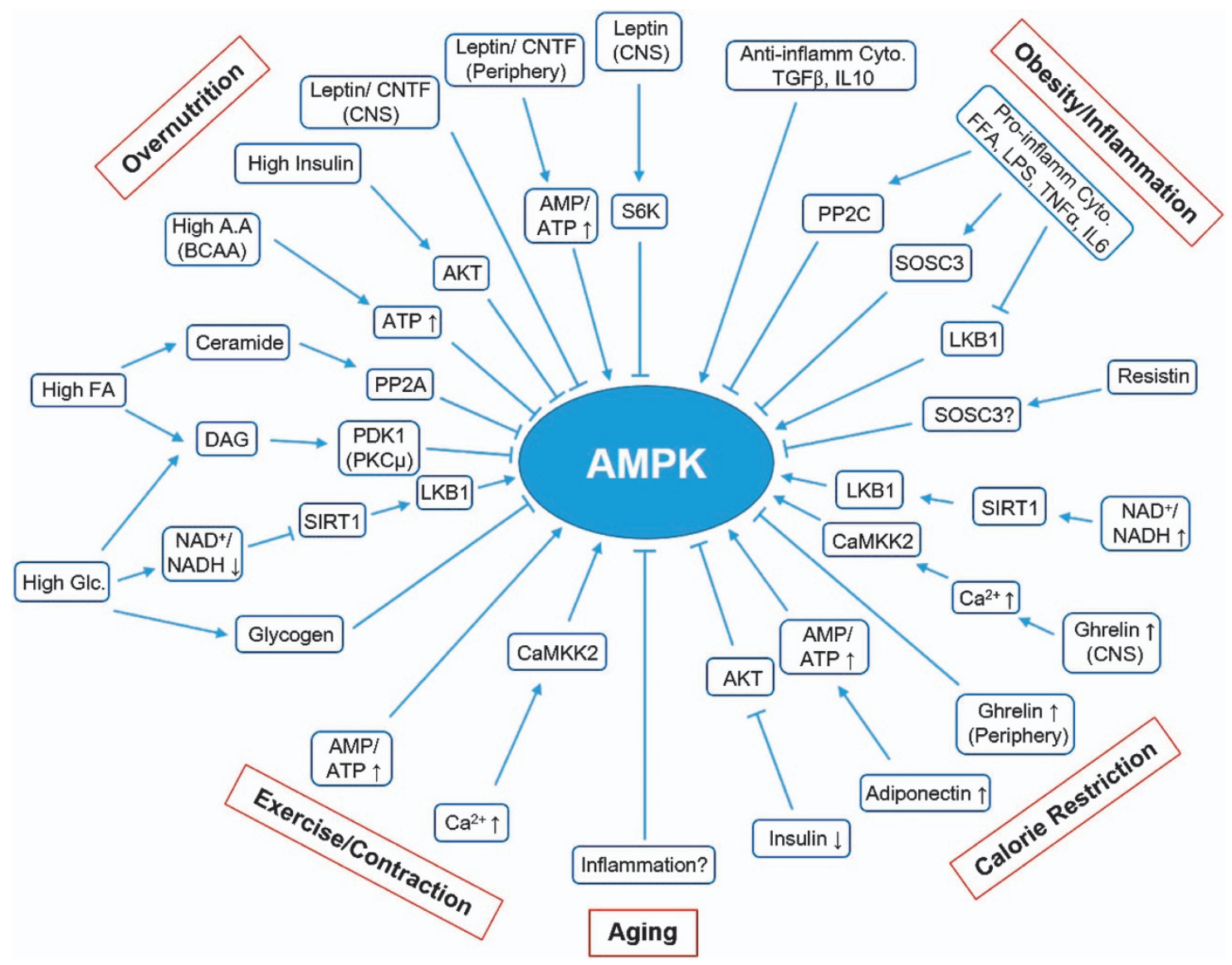

Figure 3 Physiological regulation of AMPK. A schematic summarizing the mechanisms underlying the regulation of AMPK activity under diverse physiological and pathological conditions. Arrow indicates activation, and bar-headed line indicates inhibition (see text for details).

\section{Overnutrition}

Accumulating data suggest that overnutrition and obesity are critical risk factors for modern chronic diseases, including insulin resistance, diabetes and cancer. Notably, the accumulation of three major nutrients, glucose, FAs and amino acids are suggested to suppress AMPK and contribute to insulin resistance. ${ }^{84}$ High glucose levels inhibit AMPK through mechanisms that do not affect the AMP/ATP ratio. ${ }^{85-87}$ First, the reduced expression or indirect inhibition of SIRT1 by the reduction of $\mathrm{NAD}^{+} / \mathrm{NADH}$ ratio inhibits the SIRT1-LKB1 pathway. Second, high glucose levels induce the accumulation of DAG, a PKC activator that induces the inhibitory phosphorylation of $S 485 / 491$ of the AMPK $\alpha$-subunit. Moreover, glycogen accumulation and PP2A activation in the presence of high glucose inhibits AMPK. High levels of amino acids, especially branched-chain amino acids, inhibit AMPK by increasing ATP levels and by decreasing the AMP/ATP ratio; however, data on this mechanism are inconsistent. ${ }^{88-90}$ Excess saturated FAs inhibit AMPK by inducing the accumulation of DAG and ceramides, which can activate PKC and PP2A, respectively. ${ }^{91}$ Hyperinsulinemia accompanied by excessive nutrient accumulation inhibits AMPK by inducing AKTmediated inhibitory phosphorylation at S485/491 of the AMPK $\alpha$-subunit. ${ }^{92}$
Leptin, the satiety and anti-obesity hormone secreted by adipocytes in the presence of insulin, prevents overnutrition by inhibiting AMPK in the hypothalamus to suppress appetite. In contrast, leptin activates AMPK in peripheral tissues, such as skeletal muscles, both directly by increasing the AMP/ATP ratio and indirectly through the hypothalamus-central nervous system axis involving the $\alpha$-adrenergic signal. ${ }^{93}$ However, mechanisms underlying leptin-induced differential regulation of AMPK in the hypothalamus and peripheral tissues have not been elucidated. Despite the important role of leptin in obesity control and insulin sensitization, leptin resistance has been reported in the skeletal muscles of obese individuals because of the upregulation of SOCS3, which prevents leptin-induced increase in the AMP/ATP ratio and activation of AMPK. ${ }^{94}$ Similar to leptin, an anti-obesity cytokine ciliary neurotrophic factor suppresses appetite and activates peripheral FAO by differentially regulating AMPK. ${ }^{95,96}$ Moreover, cytokine ciliary neurotrophic factor differentially regulates AMPK and exerts its physiological effects even in leptin-resistant muscles, suggesting that it can be a promising therapeutic candidate for developing anti-obesity drugs.

\section{Calorie restriction}

Calorie restriction exerts many beneficial effects against aging, diabetes and cancer. In addition to its effect on the AMP/ATP 
ratio, calorie restriction activates AMPK through multiple mechanisms. First, calorie restriction increases the $\mathrm{NAD}^{+} / \mathrm{NADH}$ ratio, which activates SIRT1, which in turn activates AMPK by deacetylating and activating LKB1. ${ }^{44,97}$ Second, as opposed to overnutrition discussed above, calorie restriction decreases blood insulin levels that may activate AMPK by decreasing its AKT-mediated inhibitory phosphorylation. ${ }^{84}$ Third, calorie restriction stimulates adiponectin secretion from adipocytes that activates AMPK in multiple tissues, including skeletal muscles. ${ }^{98}$ Interestingly, adiponectin secretion is significantly reduced in obese individuals, which partially explains reduced AMPK activity in these individuals. ${ }^{99}$ Importantly, it has been proposed that adiponectin explains many beneficial effects of calorie restriction, including insulin sensitization through activation of AMPK. 100

Ghrelin, a hunger hormone that is secreted from the stomach during calorie restriction, exerts central orexigenic and peripheral metabolic effects that are antagonized by leptin. ${ }^{101}$ Ghrelin activates AMPK in the hypothalamus by promoting intracellular calcium-induced CaMKK2 activation through the stimulation of food intake. ${ }^{101,102}$ In contrast, ghrelin inhibits AMPK in the adipose tissue and liver by exerting lipogenic and gluconeogenic effects. ${ }^{103} \mathrm{~A}$ recent study suggested that ghrelin is essential for survival during severe calorie restriction or fasting by maintaining blood glucose levels. ${ }^{104}$

\section{Obesity and inflammation}

Accumulating data suggest that chronic inflammation is a critical risk factor of modern chronic diseases, including insulin resistance, diabetes and cancer, and that obesity is a risk factor of chronic inflammation. In macrophages and adipose tissue, FFAs or lipid infusion can trigger the proinflammatory response by binding to toll-like receptor 4 , which induces insulin resistance. ${ }^{105}$ Interestingly, compelling evidence has indicated a negative association between obesity/inflammation and AMPK. ${ }^{106}$ Consistently, a recent study showed that reduced AMPK activity was associated with increased inflammation in the visceral adipose tissue and whole-body insulin resistance in morbidly obese individuals. ${ }^{107}$ Initial studies suggested that the proinflammatory cytokine TNF $\alpha$ suppressed AMPK phosphorylation and activate increasing PP2C expression in the skeletal muscles, thus contributing to insulin resistance. ${ }^{108}$ Consistently, lipid infusion stimulated the proinflammatory response in the heart by upregulating IL6 and SOSC3 expression, which decreased AMPK phosphorylation and protein levels. ${ }^{109} \mathrm{~A}$ recent study showed that LPS, FFAs and diet-induced obesity downregulated the expression of LKB1 and phosphorylation of the AMPK $\alpha 1$-subunit, a major isoform of the AMPK $\alpha$-subunit, in the adipose tissues and macrophages, suggesting that AMPK is suppressed by multiple mechanisms. ${ }^{110}$ In addition to cytokines and FFAs, resistin is involved in inflammation and insulin resistance. Resistin, which is mainly secreted by macrophages and neutrophils in humans during inflammation, promotes the proinflammatory response and induces insulin resistance. ${ }^{111-113}$ Although mechanisms underlying these effects of resistin are unclear, it has been suggested that resistin-induced insulin resistance is partially mediated by AMPK inhibition through the proinflammatory signals that induce $\mathrm{PP} 2 \mathrm{C}$ or SOSC3 expression. ${ }^{112,114,115}$ Another study showed that antiinflammatory stimuli induced by TGF $\beta$ and IL10 activate AMPK in macrophages; however, upstream kinases involved in this activation have not been identified. ${ }^{116}$ TAK1 is one possible kinase involved in the phosphorylation of AMPK during the anti-inflammatory response; however, this warrants further investigation.

Several studies suggest that AMPK exerts potent antiinflammatory effects, as summarized in Figure 2. Intensive research using various cell types indicates that AMPK inhibits inflammation by indirectly inhibiting NFKB, a key regulator of innate immunity and inflammation. Although the mechanisms underlying AMPK-induced inhibition of NFKB are not clearly understood, multiple mechanisms that suppress the expression of inflammatory genes, including activation of SIRT1, FOXO and PGC1 $\alpha$, may be involved. ${ }^{117}$ Interestingly, emerging evidence suggests that AMPK exerts anti-inflammatory effects in immune cells by switching metabolism from glycolysis to mitochondrial oxidative metabolism, such as FAO. ${ }^{106}$ Resting lymphocytes depend on mitochondrial oxidative metabolism. However, upon stimulation, metabolism in these cells is switched to glycolysis, which is associated with AMPK inhibition and rapid cell proliferation. Similarly, a recent study showed that switching from proinflammatory M1 macrophages to anti-inflammatory M2 macrophages depends on AMPK and FAO. ${ }^{118}$ These data suggest that AMPK has a key role in improving inflammation and insulin sensitivity by regulating $\mathrm{FAO}$.

\section{Exercise and muscle contraction}

Exercise-induced muscle contraction exerts many beneficial effects on health, including an insulin-sensitizing effect, largely through activation of AMPK. Muscle contraction is an energydemanding process that greatly increases ATP turnover by over 100 -fold, and induces rapid accumulation of ADP and AMP in an intensity-dependent manner. ${ }^{119}$ In addition, muscle contraction depolarizes $\mathrm{T}$-tubules that induce calcium release from the sarcoplasmic reticulum in muscle cells. ${ }^{120}$ Muscle contraction-induced increases in energy stress and calcium levels promote LKB1- and CaMKK2-mediated AMPK activation, respectively.

\section{Aging}

Because metabolism and calorie restriction are well-recognized regulators of aging, several studies on aging have focused on AMPK. Recent studies have shown that AMPK activation in response to various stimuli, such as exercise and muscle contraction, gradually declines during aging. ${ }^{121}$ Although mechanisms underlying this have not been elucidated, it is possible that the age-related increase in chronic inflammation levels suppresses AMPK activation in aged tissues. ${ }^{122}$ Importantly, numerous studies have shown that AMPK plays a 
crucial role in regulating longevity and calorie restrictioninduced lifespan extension in worms, fruit flies, and rodents. Intensive research has identified several key AMPK-regulated pro-longevity pathways, including inhibition of CRTC-1/ CREB, NFKB, and mTORC1 and activation of SIRT1, NRF2, FOXO1, and ULK1, which induce antioxidant defense, anti-inflammation, and autophagy. ${ }^{121}$

\section{ROLE OF AMPK IN DIABETES AND CANCER: LESSONS FROM TWO OLD DRUGS}

\section{Type-2 diabetes}

Type-2 diabetes is a metabolic syndrome caused by insulin resistance that induces hyperglycemia, hyperinsulinemia and hyperlipidemia. Intensive research has shown that prolonged exposure to excessive nutrients is one of the critical risk factors of insulin resistance. ${ }^{84}$ High FFAs can drive insulin resistance through DAG accumulation and PKC activation, which impairs insulin signaling by phosphorylating (IRS)-1/2, the insulin receptor substrate in the skeletal muscles, adipocytes and the liver. ${ }^{123,124}$ In addition, high amino acids (especially BCAAs) and insulin elicit mTORC1 hyperactivity, which impairs insulin signaling through p70S6K-induced IRS-1/2 phosphorylation. ${ }^{125,126}$ mTORC1 hyperactivity also elicits insulin resistance through ER stress, which induces ROS generation and chronic inflammation. ${ }^{125,127}$ Notably, FFAs can induce chronic inflammation both directly by activating TLR4 signaling ${ }^{105}$ and indirectly through ER stress. ${ }^{128,129}$ Importantly, all these conditions are associated with reduced AMPK activity (Figure 3). As shown in Figures 2 and 4, AMPK activation improves insulin sensitivity by inhibiting lipogenesis (ACC1, SREBP1c), protein synthesis (mTORC1) and lipolysis (HSL), and by activating FAO (ACC2). These pathways are associated with reduced inhibitory phosphorylation of IRS-1/2, ER stress/ROS, FFAs and chronic inflammation. Indeed, metformin, an indirect activator of AMPK, is the most frequently prescribed antidiabetic drug for type-2 diabetic patients. Therefore, AMPK-activating agents would be beneficial for both preventing and treating patients with type- 2 diabetes.

\section{Cancer: initiation and promotion vs progression and metastasis}

Tumor suppressor LKB1 functions as an upstream kinase, and mTORC1 functions as a downstream effector of AMPK. Therefore, AMPK activation would be a promising therapeutic strategy because it inhibits mTORC1. However, as extensively discussed, 2,27,130 the role of AMPK in cancer is complicated, similar to a double-edged sword. Previous studies reported that LKB1 is mutated in $20-30 \%$ of patients with cervical and lung cancers. Recent cancer genomic studies reported that several AMPK subunits are frequently overexpressed in cervical and lung cancers. ${ }^{131,132} \mathrm{~A}$ recent study also showed that

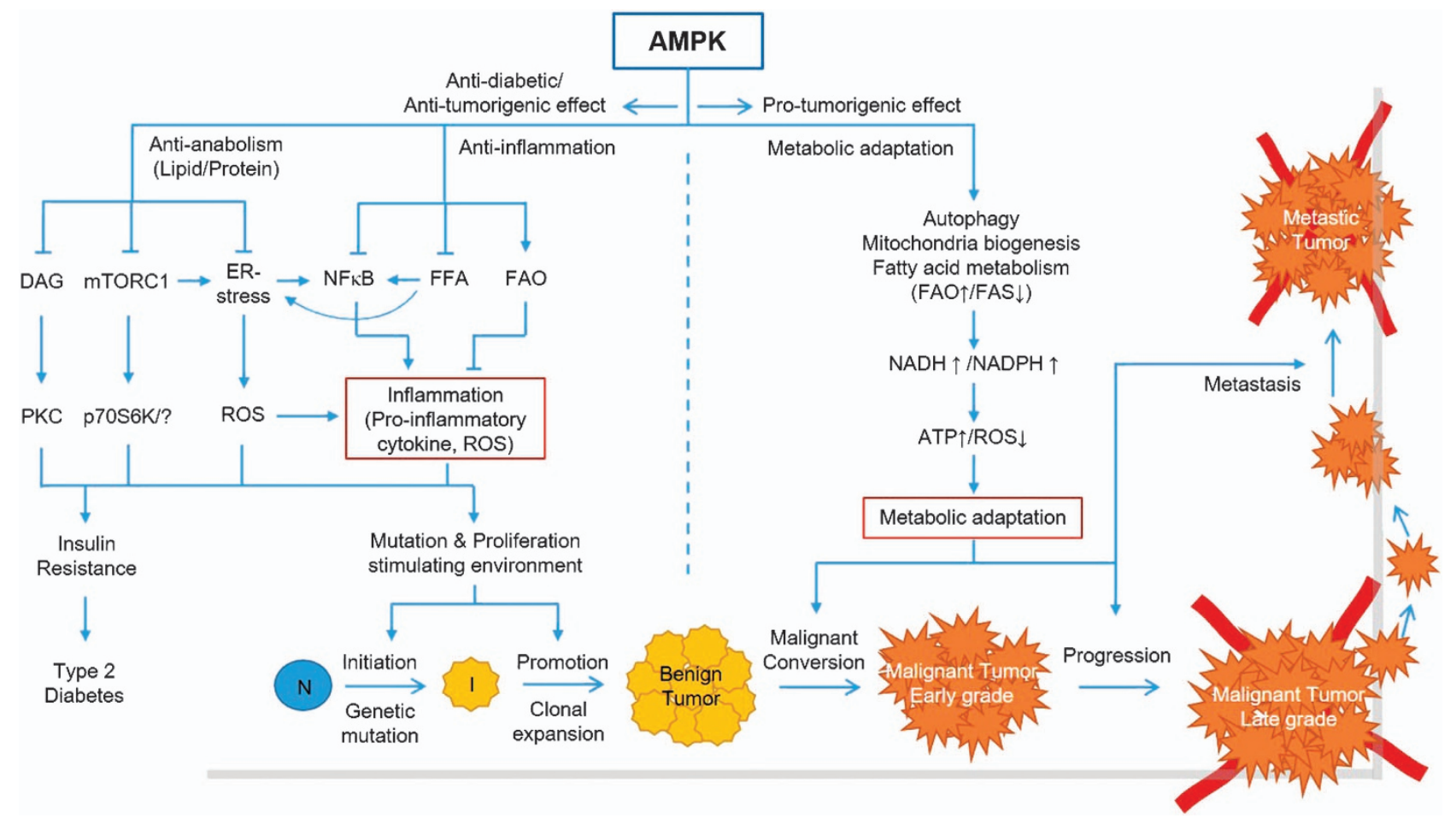

Figure 4 Integrative role of AMPK in diabetes and cancer. This model describes the integrative role of AMPK in diabetes and cancer. AMPK exerts anti-inflammatory effects largely by regulating FA metabolism, NFKB and ER stress, indicating that AMPK activators can be used for both preventing and treating insulin resistance and diabetes. The anti-inflammatory effects of AMPK also prevent cancer by inhibiting the cancer initiation and promotion stages. However, AMPK activation can also promote malignant conversion, progression and metastasis by enabling metabolic adaptation of tumor cells. Arrow indicates activation, bar-headed line indicates inhibition (see text for details). N, normal cells; I, initiated cells. 
MAGE-A3/6 and TRIM28 E3 ubiquitin ligase, which are overexpressed in many cancers, induce cancer-specific AMPK degradation. In contrast, another study showed that SKP2driven LKB1 ubiquitination in cancer cells increases its activity toward AMPK activation and promotes tumor growth. ${ }^{23,46}$ As shown in Figure 4, one possible explanation for this discrepancy in the role of AMPK in cancer is the timing of modification, mutation, or overexpression of LKB1 or AMPK. The theory of multistep carcinogenesis indicates that the tumor initiation stage, which is characterized by the introduction of DNA mutations in normal chromosomes, favors the formation of a stressful and proinflammatory environment for inducing genetic mutations. ${ }^{133}$ Inactivation of the LKB1-AMPK pathway during this stage may facilitate both cell growth and proliferation by activating mTORC1 and anabolic pathways, and by introducing genetic mutations through the augmentation of oxidative stress and proinflammatory response, largely through dysregulation of FA metabolism (Figure 4). In fact, this model can be supported by a recent finding that LKB1 deficiency promotes neutrophil recruitment and proinflammatory cytokine production in the lung tumor microenvironment. ${ }^{134}$ After the introduction of multiple genetic mutations and growth of cells into large clones such as benign tumors, the cells need to adapt and survive more severe metabolic and oxidative stress and proinflammatory environments to completely transform into malignant tumor cells (malignant conversion and progression stage). In such cases, activation of the LKB1-AMPK pathway would be beneficial for tumors because it promotes metabolic adaptation. Interestingly, this is also largely achieved by the regulation of FA metabolism, which contributes to the maintenance of NADH and NADPH levels, increases ATP levels and decreases ROS levels (Figure 4).

This view is supported by the findings that LKB1 deletion results in the formation of benign intestinal polyps that are resistant to transformation and that expression of the AMPK $\alpha 2$-subunit is suppressed in grades I and II human gastric cancers but increased in grades III and IV human gastric cancers. ${ }^{135,136}$ This view also points out the conflicting roles of FA metabolism in different tumor stages because FAO activation and FAS inhibition can prevent early stages but promote late stages of carcinogenesis (Figure 4). However, this model does not explain how tumor cells in the initiation stage that harbor mutations in the gene encoding LKB1 survive malignant conversion and progression, and develop into malignant tumors. This could be explained by the possibility that malignant transformation of tumor cells could be induced by the co-occurrence of complementing genetic mutations or activation of other AMPK-activating pathways involving CaMKK2 or TAK1. ${ }^{27,130,137}$ Therefore, it is necessary to distinguish between the roles of AMPK in cancer depending on the stages of carcinogenesis. Moreover, this suggests that AMPK activation is beneficial for cancer prevention but not for cancer treatment. Rather, AMPK inhibition could be used for treating established cancers by inhibiting stress adaptation and survival.
Lessons from two old drugs: anti-inflammation as a converging point and key mechanism for preventing both diabetes and cancer by AMPK activation

A recent study showed that salicylate, a natural product and in vivo metabolite of the anti-inflammatory drug aspirin, directly activates AMPK by binding to its $\beta 1$-subunit. ${ }^{138}$ This direct effect on AMPK activation could explain the antiinflammatory effect of aspirin. Moreover, a previous study found that aspirin reduces circulating FFA and TG levels in obese patients with type-2 diabetes and increases FAO during fasting in healthy humans, which can be explained by the direct effect of aspirin on AMPK activation. ${ }^{139,140}$ Interestingly, aspirin exerts chemopreventive effects and is used for cancer prevention. ${ }^{141}$ The critical role of AMPK in metabolism and inflammation suggests that aspirin could be effective for treating insulin resistance and diabetes through AMPK activation. In addition, anti-inflammatory effects of metformin by activating AMPK have been reported. ${ }^{142}$ Moreover, an epidemiological study showed that the use of metformin in diabetic patients significantly decreased the incidence of various cancers. ${ }^{143,144}$ Notably, chronic inflammation is one of the most critical and common risk factors of cancer and diabetes. Thus, the results of studies on aspirin and metformin suggest that AMPK-induced suppression of chronic inflammation could be a key mechanism by which activation of AMPK can prevent both diabetes and cancer (Figure 4).

\section{CONCLUDING REMARKS}

Many studies have demonstrated that AMPK is inhibited in many pathological conditions, such as inflammation, diabetes, aging and cancer, and that activation of AMPK can be beneficial to treat such diseases. Importantly, emerging data using the two old drugs known to activate AMPK suggest that the beneficial effects of AMPK activation can be largely attributed to its anti-inflammatory effects. Notably, the antiinflammatory role of AMPK is mediated at least in part by the regulation of FA metabolism (FAO $\uparrow / F A S \downarrow)$. However, caution is needed when considering the role of AMPK in cancer because it performs both anti- and pro-tumorigenic roles, depending in part on the regulation of FA metabolism. The pro-tumorigenic role of AMPK involves promotion of metabolic adaptation for cancer cell survival by regulating FA metabolism to maintain ATP and ROS levels during metabolic stress in the tumor microenvironment. Collectively, we propose two converging points, FA metabolism and inflammation, in the mechanisms by which AMPK has a role in diabetes and cancer. First, AMPK could be beneficial for preventing both diabetes and cancer by suppressing inflammation via modulation of FA metabolism. Second, AMPK can promote late stages of carcinogenesis through modulation of FA metabolism in tumor cells to induce metabolic adaptation in a metabolically stressful tumor microenvironment. Thus, AMPK activation is a promising strategy for preventing both diabetes and cancer, whereas AMPK inhibition is a novel therapeutic strategy to treat established cancers. 


\section{CONFLICT OF INTEREST}

The author declares no conflict of interest.

\section{ACKNOWLEDGEMENTS}

I thank Dr N. Hay for the helpful comments and discussion on the manuscript. This work was supported by the grants from the National R\&D Program for Cancer Control, Ministry of Health \& Welfare, Republic of Korea (S2014-A0251-00001) and Basic Science Research Program through the National Research Foundation of Korea (NRF) funded by the Ministry of Science, ICT \& Future Planning (S2014-A0403-00067).

1 Davies SP, Hawley SA, Woods A, Carling D, Haystead TA, Hardie DG. Purification of the AMP-activated protein kinase on ATP-gamma-sepharose and analysis of its subunit structure. Eur J Biochem 1994; 223: 351-357.

2 Dasgupta B, Chhipa RR. Evolving lessons on the complex role of AMPK in normal physiology and cancer. Trends Pharmacol Sci 2016; 37: 192-206.

3 Ross FA, Jensen TE, Hardie DG. Differential regulation by AMP and ADP of AMPK complexes containing different gamma subunit isoforms. Biochem J 2016; 473: 189-199.

4 Hardie DG, Ross FA, Hawley SA. AMPK: a nutrient and energy sensor that maintains energy homeostasis. Nat Rev Mol Cell Biol 2012; 13: 251-262.

5 Voss M, Paterson J, Kelsall IR, Martin-Granados C, Hastie CJ, Peggie MW et al. Ppm1E is an in cellulo AMP-activated protein kinase phosphatase. Cell Signal 2011; 23: 114-124.

6 Hawley SA, Boudeau J, Reid JL, Mustard KJ, Udd L, Makela TP et al. Complexes between the LKB1 tumor suppressor, STRAD alpha/beta and M025 alpha/beta are upstream kinases in the AMP-activated protein kinase cascade. J Biol 2003; 2 : 28.

7 Woods A, Johnstone SR, Dickerson K, Leiper FC, Fryer LG, Neumann D et al. LKB1 is the upstream kinase in the AMP-activated protein kinase cascade. Curr Biol 2003; 13: 2004-2008.

8 Shaw RJ, Kosmatka M, Bardeesy N, Hurley RL, Witters LA, DePinho RA et al. The tumor suppressor LKB1 kinase directly activates AMP-activated kinase and regulates apoptosis in response to energy stress. Proc Natl Acad Sci USA 2004; 101: 3329-3335.

9 Woods A, Dickerson K, Heath R, Hong SP, Momcilovic M, Johnstone SR et al. Ca2+/calmodulin-dependent protein kinase kinase-beta acts upstream of AMP-activated protein kinase in mammalian cells. Cell Metab 2005; 2: 21-33.

10 Hawley SA, Pan DA, Mustard KJ, Ross L, Bain J, Edelman AM et al. Calmodulin-dependent protein kinase kinase-beta is an alternative upstream kinase for AMP-activated protein kinase. Cell Metab 2005; 2: 9-19.

11 Hurley RL, Anderson KA, Franzone JM, Kemp BE, Means AR, Witters LA. The $\mathrm{Ca} 2+$ /calmodulin-dependent protein kinase kinases are AMP-activated protein kinase kinases. J Biol Chem 2005; 280: 29060-29066.

12 Davies SP, Helps NR, Cohen PT, Hardie DG. 5'-AMP inhibits dephosphorylation, as well as promoting phosphorylation, of the AMP-activated protein kinase. Studies using bacterially expressed human protein phosphatase-2C alpha and native bovine protein phosphatase-2AC. FEBS Lett 1995; 377: 421-425.

13 Oakhill JS, Chen ZP, Scott JW, Steel R, Castelli LA, Ling N et al. Betasubunit myristoylation is the gatekeeper for initiating metabolic stress sensing by AMP-activated protein kinase (AMPK). Proc Natl Acad Sci USA 2010; 107: 19237-19241.

14 McBride A, Ghilagaber S, Nikolaev A, Hardie DG. The glycogen-binding domain on the AMPK beta subunit allows the kinase to act as a glycogen sensor. Cell Metab 2009; 9: 23-34.

15 Xie M, Zhang D, Dyck JR, Li Y, Zhang H, Morishima M et al. A pivotal role for endogenous TGF-beta-activated kinase-1 in the LKB1/AMP-activated protein kinase energy-sensor pathway. Proc Natl Acad Sci USA 2006; 103: 17378-17383.

16 Momcilovic M, Hong SP, Carlson M. Mammalian TAK1 activates Snf1 protein kinase in yeast and phosphorylates AMP-activated protein kinase in vitro. J Biol Chem 2006; 281: 25336-25343.
17 Hawley SA, Ross FA, Gowans GJ, Tibarewal P, Leslie NR, Hardie DG. Phosphorylation by Akt within the ST loop of AMPK-alpha1 downregulates its activation in tumour cells. Biochem J 2014; 459: 275-287.

18 Suzuki T, Bridges D, Nakada D, Skiniotis G, Morrison SJ, Lin JD et al. Inhibition of AMPK catabolic action by GSK3. Mol Cell 2013; 50: 407-419.

19 Dagon Y, Hur E, Zheng B, Wellenstein K, Cantley LC, Kahn BB. p70S6 kinase phosphorylates AMPK on serine 491 to mediate leptin's effect on food intake. Cell Metab 2012; 16: 104-112.

20 Coughlan KA, Valentine RJ, Sudit BS, Allen K, Dagon Y, Kahn BB et al. PKD1 inhibits AMPKalpha2 through phosphorylation of serine 491 and impairs insulin signaling in skeletal muscle cells. J Biol Chem 2016; 291: 5664-5675.

21 Djouder N, Tuerk RD, Suter M, Salvioni P, Thali RF, Scholz R et al. PKA phosphorylates and inactivates AMPKalpha to promote efficient lipolysis. EMBO J 2010; 29: 469-481.

22 Qi J, Gong J, Zhao T, Zhao J, Lam P, Ye J et al. Downregulation of AMP-activated protein kinase by Cidea-mediated ubiquitination and degradation in brown adipose tissue. EMBO J 2008; 27: 1537-1548.

23 Pineda CT, Ramanathan S, Fon Tacer K, Weon JL, Potts MB, Ou YH et al. Degradation of AMPK by a cancer-specific ubiquitin ligase. Cell 2015; 160: 715-728.

24 Lee JO, Lee SK, Kim N, Kim JH, You GY, Moon JW et al. E3 ubiquitin ligase, WWP1, interacts with AMPKalpha2 and down-regulates its expression in skeletal muscle C2C12 cells. J Biol Chem 2013; 288: 4673-4680.

25 Yan Y, Ollila S, Wong IP, Vallenius T, Palvimo JJ, Vaahtomeri K et al. SUMOylation of AMPKalpha1 by PIAS4 specifically regulates mTORC1 signalling. Nat Commun 2015; 6: 8979.

26 Rubio T, Vernia S, Sanz P. Sumoylation of AMPKbeta2 subunit enhances AMP-activated protein kinase activity. Mol Biol Cell 2013; 24: 1801-1811.

27 Jeon SM, Hay N. The double-edged sword of AMPK signaling in cancer and its therapeutic implications. Arch Pharm Res 2015; 38: 346-357.

28 Cardaci S, Filomeni G, Ciriolo MR. Redox implications of AMPK-mediated signal transduction beyond energetic clues. J Cell Sci 2012; 125: 2115-2125.

29 Zmijewski JW, Banerjee S, Bae H, Friggeri A, Lazarowski ER, Abraham E. Exposure to hydrogen peroxide induces oxidation and activation of AMP-activated protein kinase. J Biol Chem 2010; 285: 33154-33164.

30 Shao D, Oka S, Liu T, Zhai P, Ago T, Sciarretta S et al. A redox-dependent mechanism for regulation of AMPK activation by Thioredoxin 1 during energy starvation. Cell Metab 2014; 19: 232-245.

31 Baba M, Hong SB, Sharma N, Warren MB, Nickerson ML, Iwamatsu A et al. Folliculin encoded by the BHD gene interacts with a binding protein, FNIP1, and AMPK, and is involved in AMPK and mTOR signaling. Proc Natl Acad Sci USA 2006; 103: 15552-15557.

32 Possik E, Jalali Z, Nouet Y, Yan M, Gingras MC, Schmeisser K et al. Folliculin regulates ampk-dependent autophagy and metabolic stress survival. PLoS Genet 2014; 10: e1004273.

33 Yan M, Gingras MC, Dunlop EA, Nouet Y, Dupuy F, Jalali Z et al. The tumor suppressor folliculin regulates AMPK-dependent metabolic transformation. J Clin Invest 2014; 124: 2640-2650.

34 Budanov AV, Karin M. p53 target genes sestrin1 and sestrin2 connect genotoxic stress and mTOR signaling. Cell 2008; 134: 451-460.

35 Zhang YL, Guo H, Zhang CS, Lin SY, Yin Z, Peng Y et al. AMP as a lowenergy charge signal autonomously initiates assembly of AXIN-AMPKLKB1 complex for AMPK activation. Cell Metab 2013; 18: 546-555.

36 Liang J, Xu ZX, Ding Z, Lu Y, Yu Q, Werle KD et al. Myristoylation confers noncanonical AMPK functions in autophagy selectivity and mitochondrial surveillance. Nat Commun 2015; 6: 7926.

37 Suzuki A, Okamoto S, Lee S, Saito K, Shiuchi T, Minokoshi Y. Leptin stimulates fatty acid oxidation and peroxisome proliferator-activated receptor alpha gene expression in mouse $\mathrm{C} 2 \mathrm{C} 12$ myoblasts by changing the subcellular localization of the alpha2 form of AMP-activated protein kinase. Mol Cell Biol 2007; 27: 4317-4327.

38 Turnley AM, Stapleton D, Mann RJ, Witters LA, Kemp BE, Bartlett PF. Cellular distribution and developmental expression of AMP-activated protein kinase isoforms in mouse central nervous system. J. Neurochem 1999; 72: 1707-1716.

39 Xie Z, Dong Y, Scholz R, Neumann D, Zou MH. Phosphorylation of LKB1 at serine 428 by protein kinase $\mathrm{C}$-zeta is required for metformin-enhanced activation of the AMP-activated protein kinase in endothelial cells. Circulation 2008; 117: 952-962. 
40 Xie Z, Dong Y, Zhang M, Cui MZ, Cohen RA, Riek U et al. Activation of protein kinase $\mathrm{C}$ zeta by peroxynitrite regulates LKB1-dependent AMP-activated protein kinase in cultured endothelial cells. J Biol Chem 2006; 281: 6366-6375.

41 Zhu H, Moriasi CM, Zhang M, Zhao Y, Zou MH. Phosphorylation of serine 399 in LKB1 protein short form by protein kinase Czeta is required for its nucleocytoplasmic transport and consequent AMP-activated protein kinase (AMPK) activation. J Biol Chem 2013; 288: 16495-16505.

42 Xie Z, Dong Y, Zhang J, Scholz R, Neumann D, Zou MH. Identification of the serine 307 of LKB1 as a novel phosphorylation site essential for its nucleocytoplasmic transport and endothelial cell angiogenesis. Mol Cell Biol 2009; 29: 3582-3596.

43 Yamada E, Pessin JE, Kurland IJ, Schwartz GJ, Bastie CC. Fyn-dependent regulation of energy expenditure and body weight is mediated by tyrosine phosphorylation of LKB1. Cell Metab 2010; 11: 113-124.

44 Lan F, Cacicedo JM, Ruderman N, Ido Y. SIRT1 modulation of the acetylation status, cytosolic localization, and activity of LKB1. Possible role in AMP-activated protein kinase activation. J Biol Chem 2008; 283: 27628-27635.

45 Ritho J, Arold ST, Yeh ET. A critical SUMO1 modification of LKB1 regulates AMPK activity during energy stress. Cell Rep 2015; 12: 734-742.

46 Lee SW, Li CF, Jin G, Cai Z, Han F, Chan CH et al. Skp2-dependent ubiquitination and activation of LKB1 is essential for cancer cell survival under energy stress. Mol Cell 2015; 57: 1022-1033.

47 Calamaras TD, Lee C, Lan F, Ido Y, Siwik DA, Colucci WS. Post-translational modification of serine/threonine kinase LKB1 via adduction of the reactive lipid species 4-hydroxy-trans-2-nonenal (HNE) at lysine residue 97 directly inhibits kinase activity. J Biol Chem 2012; 287: 42400-42406.

48 Wagner TM, Mullally JE, Fitzpatrick FA. Reactive lipid species from cyclooxygenase-2 inactivate tumor suppressor LKB1/STK11: cyclopentenone prostaglandins and 4-hydroxy-2-nonenal covalently modify and inhibit the AMP-kinase kinase that modulates cellular energy homeostasis and protein translation. J Biol Chem 2006; 281: 2598-2604.

49 Li Y, Xu S, Mihaylova MM, Zheng B, Hou X, Jiang B et al. AMPK phosphorylates and inhibits SREBP activity to attenuate hepatic steatosis and atherosclerosis in diet-induced insulin-resistant mice. Cell Metab 2011; 13: 376-388.

50 Hardie DG, Pan DA. Regulation of fatty acid synthesis and oxidation by the AMP-activated protein kinase. Biochem Soc Trans 2002; 30: 1064-1070.

51 Muoio DM, Seefeld K, Witters LA, Coleman RA. AMP-activated kinase reciprocally regulates triacylglycerol synthesis and fatty acid oxidation in liver and muscle: evidence that sn-glycerol-3-phosphate acyltransferase is a novel target. Biochem J 1999; 338: 783-791.

52 Carling D, Clarke PR, Zammit VA, Hardie DG. Purification and characterization of the AMP-activated protein kinase. Copurification of acetyl-CoA carboxylase kinase and 3-hydroxy-3-methylglutaryl-CoA reductase kinase activities. Eur J Biochem 1989; 186: 129-136.

53 Habets DD, Coumans WA, El Hasnaoui M, Zarrinpashneh E, Bertrand L, Viollet $\mathrm{B}$ et al. Crucial role for LKB1 to AMPKalpha2 axis in the regulation of CD36-mediated long-chain fatty acid uptake into cardiomyocytes. Biochim Biophys Acta 2009; 1791: 212-219.

54 Garton AJ, Yeaman SJ. Identification and role of the basal phosphorylation site on hormone-sensitive lipase. Eur J Biochem 1990; 191: 245-250.

55 Daval M, Diot-Dupuy F, Bazin R, Hainault I, Viollet B, Vaulont S et al. Anti-lipolytic action of AMP-activated protein kinase in rodent adipocytes. J Biol Chem 2005; 280: 25250-25257.

56 Taylor EB, An D, Kramer HF, Yu H, Fujii NL, Roeckl KS et al. Discovery of TBC1D1 as an insulin-, AICAR-, and contraction-stimulated signaling nexus in mouse skeletal muscle. J Biol Chem 2008; 283: 9787-9796.

57 Wu N, Zheng B, Shaywitz A, Dagon Y, Tower C, Bellinger G et al. AMPK dependent degradation of TXNIP upon energy stress leads to enhanced glucose uptake via GLUT1. Mol Cell 2013; 49: 1167-1175.

58 Zheng D, MacLean PS, Pohnert SC, Knight JB, Olson AL, Winder WW et al. Regulation of muscle GLUT-4 transcription by AMP-activated protein kinase. J Appl Physiol (1985) 2001; 91: 1073-1083.

59 Stoppani J, Hildebrandt AL, Sakamoto K, Cameron-Smith D, Goodyear LJ, Neufer PD. AMP-activated protein kinase activates transcription of the UCP3 and HKII genes in rat skeletal muscle. Am J Physiol Endocrinol Metab 2002; 283: E1239-E1248.

60 Marsin AS, Bertrand L, Rider MH, Deprez J, Beauloye C, Vincent MF et al. Phosphorylation and activation of heart PFK-2 by AMPK has a role in the stimulation of glycolysis during ischaemia. Curr Biol 2000; 10: 1247-1255.
61 Marsin AS, Bouzin C, Bertrand L, Hue L. The stimulation of glycolysis by hypoxia in activated monocytes is mediated by AMP-activated protein kinase and inducible 6-phosphofructo-2-kinase. J Biol Chem 2002; 277: 30778-30783.

62 Hunter RW, Treebak JT, Wojtaszewski JFP, Sakamoto K. Molecular mechanism by which AMP-activated protein kinase activation promotes glycogen accumulation in muscle. Diabetes 2011; 60: 766-774.

63 Koo SH, Flechner L, Qi L, Zhang X, Screaton RA, Jeffries S et al. The CREB coactivator TORC2 is a key regulator of fasting glucose metabolism. Nature 2005; 437: 1109-1111.

64 Leclerc I, Lenzner C, Gourdon L, Vaulont S, Kahn A, Viollet B. Hepatocyte nuclear factor-4alpha involved in type 1 maturity-onset diabetes of the young is a novel target of AMP-activated protein kinase. Diabetes 2001; 50: 1515-1521.

65 Mihaylova MM, Vasquez DS, Ravnskjaer K, Denechaud PD, Yu RT, Alvarez JG et al. Class Ila histone deacetylases are hormone-activated regulators of FOXO and mammalian glucose homeostasis. Cell 2011; 145: 607-621.

66 Hoppe S, Bierhoff H, Cado I, Weber A, Tiebe M, Grummt I et al. AMPactivated protein kinase adapts rRNA synthesis to cellular energy supply. Proc Natl Acad Sci USA 2009; 106: 17781-17786.

67 Leprivier G, Remke M, Rotblat B, Dubuc A, Mateo AR, Kool M et al. The eEF2 kinase confers resistance to nutrient deprivation by blocking translation elongation. Cell 2013; 153: 1064-1079.

68 Mizrachy-Schwartz S, Kravchenko-Balasha N, Ben-Bassat H, Klein S, Levitzki A. Optimization of energy-consuming pathways towards rapid growth in HPV-transformed cells. PLOS ONE 2007; 2: e628.

69 Mizrachy-Schwartz S, Cohen N, Klein S, Kravchenko-Balasha N, Levitzki A. Up-regulation of AMP-activated protein kinase in cancer cell lines is mediated through c-Src activation. J Biol Chem 2011; 286: 15268-15277.

70 Egan DF, Shackelford DB, Mihaylova MM, Gelino S, Kohnz RA, Mair W et al. Phosphorylation of ULK1 (hATG1) by AMP-activated protein kinase connects energy sensing to mitophagy. Science 2011; 331: 456-461.

$71 \mathrm{Kim} \mathrm{J}$, Kundu M, Viollet B, Guan KL. AMPK and mTOR regulate autophagy through direct phosphorylation of Ulk1. Nat. Cell Biol 2011; 13: $132-141$.

72 O'Neill HM, Maarbjerg SJ, Crane JD, Jeppesen J, Jorgensen SB, Schertzer $\mathrm{JD}$ et al. AMP-activated protein kinase (AMPK) betalbeta2 muscle null mice reveal an essential role for AMPK in maintaining mitochondrial content and glucose uptake during exercise. Proc Natl Acad Sci USA 2011; 108: 16092-16097.

73 Winder WW, Holmes BF, Rubink DS, Jensen EB, Chen M, Holloszy JO. Activation of AMP-activated protein kinase increases mitochondrial enzymes in skeletal muscle. J Appl Physiol (1985) 2000; 88: 2219-2226.

74 Lin J, Handschin C, Spiegelman BM. Metabolic control through the PGC-1 family of transcription coactivators. Cell Metab 2005; 1: 361-370.

75 Jager S, Handschin C, St-Pierre J, Spiegelman BM. AMP-activated protein kinase (AMPK) action in skeletal muscle via direct phosphorylation of PGC-1alpha. Proc Natl Acad Sci USA 2007; 104: 12017-12022.

76 Fulco M, Cen Y, Zhao P, Hoffman EP, McBurney MW, Sauve AA et al. Glucose restriction inhibits skeletal myoblast differentiation by activating SIRT1 through AMPK-mediated regulation of Nampt. Dev Cell 2008; 14: 661-673.

77 Canto C, Gerhart-Hines Z, Feige JN, Lagouge M, Noriega L, Milne JC et al. AMPK regulates energy expenditure by modulating NAD+ metabolism and SIRT1 activity. Nature 2009; 458: 1056-1060.

78 Chaube B, Malvi P, Singh SV, Mohammad N, Viollet B, Bhat MK. AMPK maintains energy homeostasis and survival in cancer cells via regulating p38/PGC-1 $\alpha$-mediated mitochondrial biogenesis. Cell Death Discov 2015; 1: 15063.

79 Greer EL, Oskoui PR, Banko MR, Maniar JM, Gygi MP, Gygi SP et al. The energy sensor AMP-activated protein kinase directly regulates the mammalian FOXO3 transcription factor. J Biol Chem 2007; 282 . 30107-30119.

80 Li XN, Song J, Zhang L, LeMaire SA, Hou X, Zhang C et al. Activation of the AMPK-FOXO3 pathway reduces fatty acid-induced increase in intracellular reactive oxygen species by upregulating thioredoxin. Diabetes 2009; 58: 2246-2257.

81 Zimmermann K, Baldinger J, Mayerhofer B, Atanasov AG, Dirsch VM, Heiss EH. Activated AMPK boosts the Nrf2/HO-1 signaling axis-a role for the unfolded protein response. Free Radic Biol Med 2015; 88: 417-426. 
82 Naveira LN, Mercado N, Ito K. AMPK signalling regulates Nrf2 localization and activity via sirtuins in a monocytic cell line. Eur Respir J 2011; 38: Suppl 55.

83 Jeon S-M, Chandel NS, Hay N. AMPK regulates NADPH homeostasis to promote tumour cell survival during energy stress. Nature 2012; 485: 661-665.

84 Coughlan KA, Valentine RJ, Ruderman NB, Saha AK. Nutrient excess in AMPK downregulation and insulin resistance. J Endocrinol Diabetes Obes 2013; 1: 1008

85 Coughlan KA, Balon TW, Valentine RJ, Petrocelli R, Schultz V, Brandon A et al. Nutrient excess and AMPK downregulation in incubated skeletal muscle and muscle of glucose infused rats. PLOS ONE 2015; 10: e0127388.

86 Itani SI, Saha AK, Kurowski TG, Coffin HR, Tornheim K, Ruderman NB. Glucose autoregulates its uptake in skeletal muscle: involvement of AMPactivated protein kinase. Diabetes 2003; 52: 1635-1640.

87 Kraegen EW, Saha AK, Preston E, Wilks D, Hoy AJ, Cooney GJ et al. Increased malonyl-CoA and diacylglycerol content and reduced AMPK activity accompany insulin resistance induced by glucose infusion in muscle and liver of rats. Am J Physiol Endocrinol Metab 2006; 290: E471-E479.

88 Saha AK, Xu XJ, Lawson E, Deoliveira R, Brandon AE, Kraegen EW et al. Downregulation of AMPK accompanies leucine- and glucose-induced increases in protein synthesis and insulin resistance in rat skeletal muscle. Diabetes 2010; 59: 2426-2434.

89 Du M, Shen QW, Zhu MJ, Ford SP. Leucine stimulates mammalian target of rapamycin signaling in $\mathrm{C} 2 \mathrm{C} 12$ myoblasts in part through inhibition of adenosine monophosphate-activated protein kinase. J Anim Sci 2007; 85: 919-927.

90 Saha AK, Xu XJ, Balon TW, Brandon A, Kraegen EW, Ruderman NB. Insulin resistance due to nutrient excess: is it a consequence of AMPK downregulation? Cell Cycle 2011; 10: 3447-3451.

91 Wu Y, Song P, Xu J, Zhang M, Zou MH. Activation of protein phosphatase $2 \mathrm{~A}$ by palmitate inhibits AMP-activated protein kinase. J Biol Chem 2007; 282: 9777-9788.

92 Valentine RJ, Coughlan KA, Ruderman NB, Saha AK. Insulin inhibits AMPK activity and phosphorylates AMPK Ser(4)(8)(5)/(4)(9)(1) through Akt in hepatocytes, myotubes and incubated rat skeletal muscle. Arch Biochem Biophys 2014; 562: 62-69.

93 Minokoshi Y, Kim Y-B, Peroni OD, Fryer LGD, Muller C, Carling D et al. Leptin stimulates fatty-acid oxidation by activating AMP-activated protein kinase. Nature 2002; 415: 339-343.

94 Steinberg GR, McAinch AJ, Chen MB, O'Brien PE, Dixon JB, CameronSmith $D$ et al. The suppressor of cytokine signaling 3 inhibits leptin activation of AMP-kinase in cultured skeletal muscle of obese humans. J Clin Endocrinol Metab 2006; 91: 3592-3597.

95 Watt MJ, Dzamko N, Thomas WG, Rose-John S, Ernst M, Carling D et al. CNTF reverses obesity-induced insulin resistance by activating skeletal muscle AMPK. Nat Med 2006; 12: 541-548.

96 Steinberg GR, Watt MJ, Fam BC, Proietto J, Andrikopoulos S, Allen AM et al. Ciliary neurotrophic factor suppresses hypothalamic AMP-kinase signaling in leptin-resistant obese mice. Endocrinology 2006; 147: 3906-3914.

97 Ruderman NB, Xu XJ, Nelson L, Cacicedo JM, Saha AK, Lan F et al. AMPK and SIRT1: a long-standing partnership? Am J Physiol Endocrinol Metab 2010; 298: E751-E760.

98 Yamauchi T, Kamon J, Minokoshi Y, Ito Y, Waki H, Uchida S et al. Adiponectin stimulates glucose utilization and fatty-acid oxidation by activating AMP-activated protein kinase. Nat Med 2002; 8: 1288-1295.

99 Nigro E, Scudiero O, Monaco ML, Palmieri A, Mazzarella G, Costagliola C et al. New insight into adiponectin role in obesity and obesity-related diseases. Biomed Res Int 2014; 2014: 658913.

100 Zhu M, Miura J, Lu LX, Bernier M, DeCabo R, Lane MA et al. Circulating adiponectin levels increase in rats on caloric restriction: the potential for insulin sensitization. Exp Gerontol 2004; 39: 1049-1059.

101 Andrews ZB. Central mechanisms involved in the orexigenic actions of ghrelin. Peptides 2011; 32: 2248-2255.

102 Anderson KA, Ribar TJ, Lin F, Noeldner PK, Green MF, Muehlbauer MJ et al. Hypothalamic CaMKK2 contributes to the regulation of energy balance. Cell Metab 2008; 7: 377-388.

103 Kola B, Hubina E, Tucci SA, Kirkham TC, Garcia EA, Mitchell SE et al. Cannabinoids and ghrelin have both central and peripheral metabolic and cardiac effects via AMP-activated protein kinase. J Biol Chem 2005; 280: 25196-25201.
104 Li RL, Sherbet DP, Elsbernd BL, Goldstein JL, Brown MS, Zhao TJ. Profound hypoglycemia in starved, ghrelin-deficient mice is caused by decreased gluconeogenesis and reversed by lactate or fatty acids. J Biol Chem 2012; 287: 17942-17950.

105 Shi H, Kokoeva MV, Inouye K, Tzameli I, Yin H, Flier JS. TLR4 links innate immunity and fatty acid-induced insulin resistance. J Clin Invest 2006; 116: 3015-3025.

106 O'Neill LA, Hardie DG. Metabolism of inflammation limited by AMPK and pseudo-starvation. Nature 2013; 493: 346-355.

107 Gauthier MS, O'Brien EL, Bigornia S, Mott M, Cacicedo JM, Xu XJ et al. Decreased AMP-activated protein kinase activity is associated with increased inflammation in visceral adipose tissue and with whole-body insulin resistance in morbidly obese humans. Biochem Biophys Res Commun 2011; 404: 382-387.

108 Steinberg GR, Michell BJ, van Denderen BJ, Watt MJ, Carey AL, Fam BC et al. Tumor necrosis factor alpha-induced skeletal muscle insulin resistance involves suppression of AMP-kinase signaling. Cell Metab 2006; 4: 465-474.

109 Ko HJ, Zhang Z, Jung DY, Jun JY, Ma Z, Jones KE et al. Nutrient stress activates inflammation and reduces glucose metabolism by suppressing AMP-activated protein kinase in the heart. Diabetes 2009; 58: 2536-2546.

110 Yang Z, Kahn BB, Shi H, Xue BZ. Macrophage alpha1 AMP-activated protein kinase (alpha1AMPK) antagonizes fatty acid-induced inflammation through SIRT1. J Biol Chem 2010; 285: 19051-19059.

111 Jiang S, Park DW, Tadie JM, Gregoire M, Deshane J, Pittet JF et al. Human resistin promotes neutrophil proinflammatory activation and neutrophil extracellular trap formation and increases severity of acute lung injury. J Immunol 2014; 192: 4795-4803.

112 Park HK, Qatanani M, Briggs ER, Ahima RS, Lazar MA. Inflammatory induction of human resistin causes insulin resistance in endotoxemic mice. Diabetes 2011; 60: 775-783.

113 Bostrom EA, Tarkowski A, Bokarewa M. Resistin is stored in neutrophil granules being released upon challenge with inflammatory stimuli. Biochim Biophys Acta 2009; 1793: 1894-1900.

114 Luo Z, Zhang Y, Li F, He J, Ding H, Yan L et al. Resistin induces insulin resistance by both AMPK-dependent and AMPK-independent mechanisms in HepG2 cells. Endocrine 2009; 36: 60-69.

115 Pirvulescu M, Manduteanu I, Gan AM, Stan D, Simion V, Butoi E et al. A novel pro-inflammatory mechanism of action of resistin in human endothelial cells: up-regulation of SOCS3 expression through STAT3 activation. Biochem Biophys Res Commun 2012; 422: 321-326.

116 Sag D, Carling D, Stout RD, Suttles J. Adenosine 5'-monophosphateactivated protein kinase promotes macrophage polarization to an antiinflammatory functional phenotype. J Immunol 2008; 181: 8633-8641.

117 Salminen A, Hyttinen JM, Kaarniranta K. AMP-activated protein kinase inhibits NF-kappaB signaling and inflammation: impact on healthspan and lifespan. J Mol Med (Berl.) 2011; 89: 667-676.

118 Galic S, Fullerton MD, Schertzer JD, Sikkema S, Marcinko K, Walkley CR et al. Hematopoietic AMPK betal reduces mouse adipose tissue macrophage inflammation and insulin resistance in obesity. J Clin Invest 2011; 121: 4903-4915.

119 Sahlin K, Tonkonogi M, Soderlund K. Energy supply and muscle fatigue in humans. Acta Physiol Scand 1998; 162: 261-266.

120 O'Neill HM. AMPK and exercise: glucose uptake and insulin sensitivity. Diabetes Metab J 2013; 37: 1-21.

121 Salminen A, Kaarniranta K. AMP-activated protein kinase (AMPK) controls the aging process via an integrated signaling network. Ageing Res Rev 2012; 11: 230-241.

122 Salminen A, Huuskonen J, Ojala J, Kauppinen A, Kaarniranta K, Suuronen $T$. Activation of innate immunity system during aging: NF-kB signaling is the molecular culprit of inflamm-aging. Ageing Res Rev 2008; 7: 83-105.

123 Szendroedi J, Yoshimura T, Phielix E, Koliaki C, Marcucci M, Zhang D et al. Role of diacylglycerol activation of PKCtheta in lipid-induced muscle insulin resistance in humans. Proc Natl Acad Sci USA 2014; 111: 9597-9602.

124 Turban S, Hajduch E. Protein kinase C isoforms: mediators of reactive lipid metabolites in the development of insulin resistance. FEBS Lett 2011; 585: 269-274.

125 Blagosklonny MV. TOR-centric view on insulin resistance and diabetic complications: perspective for endocrinologists and gerontologists. Cell Death Dis 2013; 4: e964. 
126 Lynch CJ, Adams SH. Branched-chain amino acids in metabolic signalling and insulin resistance. Nat Rev Endocrinol 2014; 10: 723-736.

127 Ruderman NB, Carling D, Prentki M, Cacicedo JM. AMPK, insulin resistance, and the metabolic syndrome. J Clin Invest 2013; 123: 2764-2772.

128 Jiao P, Ma J, Feng B, Zhang H, Alan-Diehl J, Eugene-Chin Y et al. FFAinduced adipocyte inflammation and insulin resistance: involvement of $E R$ stress and IKK $\beta$ pathways. Obesity 2011; 19: 483-491.

129 Kawasaki N, Asada R, Saito A, Kanemoto S, Imaizumi K. Obesity-induced endoplasmic reticulum stress causes chronic inflammation in adipose tissue. Sci Rep 2012; 2: 799.

130 Jeon SM, Hay N. The dark face of AMPK as an essential tumor promoter. Cell Logist 2012; 2: 197-202.

131 Gao J, Aksoy BA, Dogrusoz U, Dresdner G, Gross B, Sumer SO et al. Integrative analysis of complex cancer genomics and clinical profiles using the cBioPortal. Sci Signal 2013; 6: pl1.

132 Cerami E, Gao J, Dogrusoz U, Gross BE, Sumer SO, Aksoy BA et al. The cBio cancer genomics portal: an open platform for exploring multidimensional cancer genomics data. Cancer Discov 2012; 2: 401-404.

133 Barrett JC. Mechanisms of multistep carcinogenesis and carcinogen risk assessment. Environ. Health Perspect 1993; 100: 9-20.

134 Koyama S, Akbay EA, Li YY, Aref AR, Skoulidis F, Herter-Sprie GS et al. STK11/LKB1 deficiency promotes neutrophil recruitment and proinflammatory cytokine production to suppress T-cell activity in the lung tumor microenvironment. Cancer Res 2016; 76: 999-1008.

$135 \mathrm{Kim}$ YH, Liang H, Liu X, Lee JS, Cho JY, Cheong JH et al. AMPKalpha modulation in cancer progression: multilayer integrative analysis of the whole transcriptome in Asian gastric cancer. Cancer Res 2012; 72: 2512-2521.

136 Bardeesy N, Sinha M, Hezel AF, Signoretti S, Hathaway NA, Sharpless NE et al. Loss of the Lkb1 tumour suppressor provokes intestinal polyposis but resistance to transformation. Nature 2002; 419: 162-167.

137 Skoulidis F, Byers LA, Diao L, Papadimitrakopoulou VA, Tong P, Izzo J et al. Co-occurring genomic alterations define major subsets of KRASmutant lung adenocarcinoma with distinct biology, immune profiles, and therapeutic vulnerabilities. Cancer Discov 2015; 5: 860-877.
138 Hawley SA, Fullerton MD, Ross FA, Schertzer JD, Chevtzoff C, Walker KJ et al. The ancient drug salicylate directly activates AMP-activated protein kinase. Science 2012; 336: 918-922.

139 Hundal RS, Petersen KF, Mayerson AB, Randhawa PS, Inzucchi S, Shoelson SE et al. Mechanism by which high-dose aspirin improves glucose metabolism in type 2 diabetes. J Clin Invest 2002; 109: 1321-1326.

140 Meex RC, Phielix E, Moonen-Kornips E, Schrauwen P, Hesselink MK. Stimulation of human whole-body energy expenditure by salsalate is fueled by higher lipid oxidation under fasting conditions and by higher oxidative glucose disposal under insulin-stimulated conditions. J Clin Endocrinol Metab 2011: 96: 1415-1423.

141 Cuzick J, Otto F, Baron JA, Brown PH, Burn J, Greenwald P et al. Aspirin and non-steroidal anti-inflammatory drugs for cancer prevention: an international consensus statement. Lancet Oncol 2009; 10: 501-507.

142 Saisho Y. Metformin and inflammation: its potential beyond glucoselowering effect. Endocr Metab Immune Disord Drug Targets 2015; 15: 196-205.

143 Evans JM, Donnelly LA, Emslie-Smith AM, Alessi DR, Morris AD. Metformin and reduced risk of cancer in diabetic patients. BMJ 2005; 330: 1304-1305.

144 Decensi A, Puntoni M, Goodwin P, Cazzaniga M, Gennari A, Bonanni B et al. Metformin and cancer risk in diabetic patients: a systematic review and meta-analysis. Cancer Prev Res (Phila) 2010; 3: 1451-1461.

(c) (1) () $\Theta$ This work is licensed under a Creative Commons Attribution-NonCommercial-NoDerivs 4.0 International License. The images or other third party material in this article are included in the article's Creative Commons license, unless indicated otherwise in the credit line; if the material is not included under the Creative Commons license, users will need to obtain permission from the license holder to reproduce the material. To view a copy of this license, visit http://creativecommons.org/licenses/by-nc-nd/4.0/ 